\title{
Eksplorasi Potensi Wisata Kuliner Untuk Pengembangan Pariwisata Di Kota Tangerang
}

\author{
Yustisia Kristiana $^{1}$, Michael Thomas Suryadi ${ }^{2}$, Samuel Riyandi Sunarya ${ }^{3}$ \\ SEKOLAH TINGGI PARIWISATA PELITA HARAPAN \\ E-mail : yustisia.kristiana@uph.edu ${ }^{1}$
}

\begin{abstract}
Nowadays, culinary tourism becomes one of the attractions to visit destination, this phenomenon can also be seen in Tangerang City. The great potential in Tangerang City is not supported with adequate information about the culinary riches of Tangerang. Many factor that cause lack of information for tourists, one of which is the lack of guidebooks and culinary references of Tangerang City. Therefore this study aims to identify the potential of culinary tourism as well as analyze the problems faced in developing a typical cuisine in the city of Tangerang. This study is qualitative research, used primary and secondary data. Method analysis used is SWOT analysis (Strengths, Weaknesses, Opportunities, and Threats). The results shows that culinary tourism in Tangerang City needed to be well-organized regarding there are threats and weaknesses in culinary tourism development.
\end{abstract}

\section{Keywords: Tourism, Culinary Tourism, Tangerang City}

Abstrak: Dewasa ini, wisata kuliner menjadi salah satu daya tarik wisatawan untuk menunjungi suatu daerah, fenomena ini juga dapat terlihat di Kota Tangerang. Potensi yang besar di Kota Tangerang belum didukung dengan informasi yang memadai mengenai kekayaan kuliner Tangerang. Banyak faktor yang menyebabkan kurangnya informasi bagi para wisatawan, salah satunya adalah belum tersedianya referensi tentang kuliner Kota Tangerang. Oleh karena itu penelitian ini bertujuan untuk mengidentifikasi potensi wisata kuliner serta menganalisis masalah-masalah yang dihadapi dalam mengembangkan kuliner khas di Kota Tangerang. Penelitian ini adalah penelitian kualitatif, serta menggunakan data primer dan sekunder. Metode analisis yang digunakan adalah analisis SWOT (Strengths, Weaknesses, Opportunities, Threats). Hasil dari penelitian menunjukkan bahwa pengelolaan wisata kuliner di Kota Tangerang masih sangat diperlukan mengingat terdapat beberapa ancaman dan kekurangan yang dimiliki dalam pengembangan wisata kuliner di Kota Tangerang.

Kata kunci: Pariwisata, Wisata Kuliner, Kota Tangerang

\subsection{Latar Belakang}

Indonesia merupakan negara kepulauan dengan jumlah pulau sebanyak 17.504 pulau yang dibagi dalam 34 provinsi (Dewan Ketahanan Nasional, 2016). Banyaknya pulau yang dimiliki Indonesia membuat negara ini memiliki keanekaragaman budaya yang berpotensi untuk dikembangkan menjadi wisata budaya. Wisata budaya merupakan suatu kegiatan wisata yang menjadikan budaya sebagai atraksi utama dan bertujuan memberikan informasi serta pengalaman mengenai kebudayaan di daerah tersebut (Raj, Griffin, dan Morpeth, 2013).

Salah satu provinsi di Indonesia yang sedang berkembang dalam bidang wisata budaya adalah Provinsi Banten. Provinsi Banten berdiri pada 4 Oktober 2000. Sebelum Banten diresmikan menjadi sebuah provinsi, Banten merupakan bagian dari Provinsi Jawa Barat. Sekarang, Provinsi Banten memiliki 4 kabupaten dan 4 kota. Keempat kabupaten yang terdapat di Provinsi Banten meliputi Kabupaten Lebak, Kabupaten Pandeglang, Kabupaten Serang, dan Kabupaten
Tangerang. Sedangkan keempat kota yang terdapat di Provinsi Banten meliputi Kota Cilegon, Kota Serang, Kota Tangerang, Kota Tangerang Selatan (Pemerintahan Provinsi Banten, 2014).

Salah satu kota yang sedang berkembang dalam bidang pariwisata di Provinsi Banten adalah Kota Tangerang. Kota Tangerang berbatasan langsung dengan tiga kota besar, yaitu DKI Jakarta, Kabupaten Tangerang, dan Kota Tangerang Selatan (Badan Pusat Statistik Kota Tangerang, 2016). Berbatasan dengan tiga kota besar menyebabkan Kota Tangerang menjadi kota industri yang besar. Meskipun Kota Tangerang merupakan kota industri yang besar, pariwisata Kota Tangerang pun berkembang. Daya tarik wisata Kota Tangerang antara lain:

Tabel 1 Daya Tarik Wisata Kota Tangerang

\begin{tabular}{|l|l|}
\hline Jenis Wisata & \multicolumn{2}{|c|}{ Daya Tarik Wisata } \\
\hline Wisata Alam & a) Pantai Tanjung \\
& Burung \\
& b) Pantai Tanjung \\
& C) Kait \\
& c) Pantai Tanjung \\
\hline
\end{tabular}




\begin{tabular}{|c|c|}
\hline Jenis Wisata & Daya Tarik Wisata \\
\hline & $\begin{array}{l}\text { Pasir } \\
\text { d) Pulau Cangkir }\end{array}$ \\
\hline $\begin{array}{l}\text { Wisata } \\
\text { Budaya }\end{array}$ & $\begin{array}{l}\text { a) Festival Cisadane } \\
\text { b) Klenteng Boen } \\
\text { San Bio } \\
\text { c) Klenteng Boen } \\
\text { Tek Bio } \\
\text { d) Klenteng Khoet } \\
\text { Goean Bio } \\
\text { e) Masjid Pintu } \\
\text { Seribu } \\
\text { f) Masjid Raya Al } \\
\text { Azhom } \\
\text { g) Museum Benteng } \\
\text { heritage } \\
\text { h) Wisata Kuliner } \\
\text { Pasar Lama }\end{array}$ \\
\hline Wisata Buatan & $\begin{array}{l}\text { a) Alun-alun Kota } \\
\text { Tangerang } \\
\text { b) Bendungan Pintu } \\
\text { Air Sepuluh } \\
\text { c) Situ Bulakan } \\
\text { d) Situ Cipondoh } \\
\text { e) Taman Buaya } \\
\text { Tanjung Pasir } \\
\text { f) Taman Potret } \\
\text { Tangerang } \\
\text { g) Taman Prestasi } \\
\text { Tangerang } \\
\text { h) Tugu Adipura }\end{array}$ \\
\hline
\end{tabular}

Sumber: BPS Kota Tangerang (2012)

Jumlah PDRB Kota Tangerang pada sektor pariwisata mengalami peningkatan pada tiga tahun terakhir. Dari 17 sektor yang tercatat dari tahun 2012 hingga tahun 2015, PDRB pada sektor pariwisata Kota Tangerang memiliki angka persen rata-rata 1,35\%. Hal tersebut dikarenakan Kota Tangerang dikenal sebagai kota industri, sehingga sektor yang memiliki PDRB tertinggi adalah sektor pengolahan atau manufacturing. Namun, melihat peningkatan PDRB pada sektor pariwisata yang selalu terjadi setiap tahunnya, membuktikan bahwa pariwisata merupakan salah satu sektor yang berkembang di Kota Tangerang.

Dengan melihat peluang industri pariwisata di Kota Tangerang, hal ini mendorong kuliner menjadi suatu daya tarik wisata. Dengan adanya wisata kuliner, makanan atau kuliner bukanlah sebagai penunjang dalam pariwisata, melainkan menjadi tujuan utama wisatawan melakukan kegiatan wisata. Kuliner yang terdapat di Kota Tangerang banyak dipengaruhi oleh beberapa suku yang dominan di Kota Tangerang, seperti suku Sunda, Betawi, dan Tionghoa. Hal ini menyebabkan beberapa kuliner khas di Kota
Tangerang mirip dengan kuliner khas di daerah sekitarnya. Biasanya perbedaan hanya terletak pada bumbu dan bahan yang digunakan. Oleh sebab itu, keunikan tersebut menjadi suatu daya tarik tersendiri bagi para wisatawan untuk melakukan wisata di Kota Tangerang. Terlebih lagi, banyak penyedia kuliner di Kota Tangerang yang menwarkan kuliner khas Kota Tangerang. Banyaknya penyedia kuliner yang memiliki nilai sejarah di Kota Tangerang belum didukung dengan referensi yang memadai. Hal ini dapat menjadi sebuah kendala bagi para wisatawan untuk melakukan wisata. Oleh karena itu, berdasarkan latar belakang yang telah diuraikan di atas, peneliti tertarik untuk melakukan penelitian tentang potensi wisata kuliner di Kota Tangerang. Tujuan dari penelitian ini adalah untuk mengidentifikasi potensi wisata kuliner di Kota Tangerang dan menganalisis masalah-masalah yang dihadapi dalam mengembangkan kuliner khas Kota Tangerang. Luaran dari penelitian ini adalah referensi mengenai wisata kuliner di Kota Tangerang dalam bentuk buku panduan.

\subsection{Tinjauan Pustaka}

Menurut Undang-undang Pemerintah Nomor 10 Tahun 2009 tentang Kepariwisataan, pariwisata adalah berbagai macam kegiatan wisata dan didukung berbagai fasilitas serta layanan yang disediakan oleh masyarakat, pengusaha, Pemerintah, dan Pemerintah Daerah. Jenis wisata dibagi menjadi tujuh jenis yaitu wisata olahraga, wisata religius, wisata agro, wisata gua, wisata belanja, wisata ekologi dan wisata kuliner (Ismayanti, 2010). Wisata kuliner sendiri merupakan jenis wisata yang tidak semata-mata hanya untuk mengenyangkan dengan memakan aneka ragam masakan khas dari daerah tujuan wisata, melainkan juga mendapatkan pengalaman menarik dengan memakan dan memasak aneka ragam makanan khas tiap daerah.

Wisata kuliner merupakan wisata yang dipengaruhi oleh adanya keinginan untuk melakukan kunjungan terhadap tempat pembuatan makanan, festival makanan, restoran, atau suatu lokasi dengan tujuan mencoba makanan (Hall et al., 2003). Selain itu, terdapat juga definisi lain mengenai wisata kuliner, yaitu segala sesuatu yang berkaitan dengan makanan sebagai subjek dan media, tujuan dan kendaraan untuk wisata, dan kegiatan dalam wisata yaitu mencicipi makanan di restoran-restoran etnik, mengunjungi festival makanan, mencoba makanan pada saat melakukan perjalanan 
wisata dan bahkan memasak di rumah (Pendit, 2003).

Menurut Sumantri (2010), makanan adalah kebutuhan pokok manusia yang dibutuhkan setiap saat dan membutuhkan pengolahan yang baik dan benar agar bermanfaat bagi tubuh. Oleh karena itu makanan merupakan kebutuhan pokok yang harus dipenuhi. Pada dasarnya makanan dipengaruhi oleh ketersediaan bahan mentah dari alam sekitar, sehingga setiap daerah memiliki ciri khas makanannya masingmasing. Menurut Harmayani, Santoso, dan Gardjito (2017), makanan tradisional adalah makanan yang diolah dari bahan pangan hasil produksi setempat, dengan proses yang telah dikuasai masyarakat dan hasilnya adalah produk yang citarasa, bentuk dan cara makannya dikenal, dan menjadi ciri khas kelompok masyarakat tertentu.

Seiring perkembangan zaman, makanan tradisional tidak hanya diproduksi secara konvensional, melainkan juga diproses menjadi suatu pangan olahan. Menurut Undang-Undang Nomor 18 Tahun 2012 tentang Pangan, pangan olahan adalah makanan hasil proses dengan cara atau metode tertentu dengan atau tanpa bahan tambahan. Sedangkan, produksi pangan adalah kegiatan atau proses menghasilkan, menyiapkan, mengolah, membuat, mengawetkan, mengemas, mengemas kembali, dan mengubah bentuk pangan.

Selain makanan, kekayaan kuliner terdiri dari minuman dan hidangan penutup. Menurut Dittmer dan Keefe (2009), minuman adalah segala bentuk cairan yang dapat diminum. Minuman biasanya dibagi menjadi dua, yaitu minuman beralkohol dan minuman nonalkohol. Sedangkan hidangan penutup adalah hidangan yang disajikan setelah hidangan utama sebagai hidangan penutup atau biasa disebut dengan istilah pencuci mulut (Ekawatiningsih, 2008).

Hasil penelitian yang dilakukan oleh Araujo (2016) menyatakan bahwa pengembangan makanan tradisional memberikan kontribusi terhadap keberlanjutan pariwisata. Selain itu, hasil penelitian Besra (2012) menyatakan bahwa wisata kuliner mempunyai prospek yang bagus untuk dikembangkan meskipun banyak menghadapi masalah yang menghambat perkembangannya. Maka dari itu, diperlukan strategi pemasaran yang sesuai untuk memasarkan jasa kuliner dan dibutuhkan dukungan dari banyak pihak terutama pemerintah.

\subsection{Metode Penelitian}

Pendekatan penelitian yang digunakan peneliti yaitu penelitian kualitatif. Penelitian kualitatif yaitu suatu penelitian ilmiah yang bertujuan untuk memahami suatu fenomena dalam konteks sosial secara alamiah dengan mengedepankan proses interaksi komunikasi yang mendalam antara peneliti dengan fenomena yang diteliti (Moleong, 2010). Jenis data yang digunakan pada penelitian ini terdiri dari data primer dan data sekunder. Data primer adalah data yang dikumpulkan melalui kuesioner ataupun wawancara untuk mencari solusi dari masalah penelitian yang ditemukan. Data primer diperoleh melalui observasi dan wawancara. Data sekunder adalah informasi yang didapatkan dari sumber yang telah ada seperti data perusahaan, data yang diperoleh dari pemerintahan, dan industri yang disediakan oleh media, website, internet, bukubuku dan lainnya (Sekaran dan Bougie, 2016). Data sekunder diperoleh melalui studi literatur (buku, jurnal, karya ilmiah dan dokumen terkait) serta data yang berasal dari instansi.

Metode analisis yang digunakan peneliti dalam melakukan penelitian yaitu metode analisis deskriptif dan metode analisis SWOT. Metode analisis deskriptif adalah metode yang digunakan untuk menganalisis data dengan cara mendeskripsikan atau menggambarkan data yang telah terkumpul sebagaimana adanya tanpa bermaksud membuat simpulan yang berlaku untuk umum atau generalisasi (Sugiyono, 2013). Metode analisis SWOT adalah sebuah analisis untuk mengidentifikasi kekuatan dan kelemahan internal serta mengidentifikasi ancaman serta peluang eksternal (Fitzsimmons dan Fitzsimmons, 2006).

\subsection{Hasil Penelitian dan Pembahasan}

Kota Tangerang merupakan kota dengan potensi wisata kuliner yang besar. Hal ini dibuktikan dengan banyaknya penyedia kuliner di kota ini yang menjual kuliner khas Kota Tangerang. Pihak Pemerintahan Kota Tangerang pun turut mendukung wisata kuliner Kota Tangerang. Salah satu cara yang dilakukan Pemerintahan Kota Tangerang adalah dengan membuat beberapa kawasan wisata kuliner di Kota Tangerang seperti Wisata Kuliner Pasar Lama dan Kuliner Laksa Kota Tangerang. Selain itu, banyak pula penyedia kuliner yang memiliki nilai sejarah dan sudah ada sejak lama.

Penyedia kuliner yang memiliki nilai sejarah dan merepresentasikan Kota Tangerang dapat dibagi menjadi tiga, yaitu:

1. Makanan

2. Minuman dan hidangan penutup 
3. Produksi pangan olahan

Berdasarkan hasil penelitian, penyedia kuliner makanan di Kota Tangerang yang memiliki potensi sebagai wisata kuliner antara lain:

1. Kuliner Laksa Kota Tangerang

2. Pondok Soto Betawi Ci Melie

3. Kwetiau Sapi 28 Tangerang

4. Gado-gado Ci Yenny

5. Bakmi DO

6. Bakmi Ayam Pasar Lama

7. Siomay Sandy

8. Ayam Goreng Borobudur

9. Restoran Ayam Goren Hj. Kokom

10. Rumah Makan Tampah Yohgun

11. Sayur Asem H. Sadeli

12. Gecom Pak Adang

13. Asinan Sewan Bedeng

14. Warung Satai $H$. Wahab

15. Satai Ayam H. Ishak

16. Satai Babi Ko Encung

17. Nasi Uduk Favorite

18. Nasi Uduk Encim Sukaria

19. Bubur Ayam Ko lyo

20. Nasi Jagal

Penyedia kuliner minuman dan hidangan penutup yang tergolong unik di Kota Tangerang yaitu:

1. Es Podeng Depan Varia

2. Kue Ape Pasar Lama

3. Es Campur Bun Tin

4. Es Selendang Mayang Babeh Sapri Modernland

Sedangkan penyedia kuliner yang merupakan produksi pangan olahan khas Kota Tangerang adalah:

1. Kecap Benteng Cap Siong Hin (SH)

2. Dodol dan Kue Keranjang Ny. Lauw

3. Mama Bolu Tape Benteng Tangerang.

Penyedia kuliner yang terdapat di Kota

Tangerang memiliki kekuatan (strengths), kelemahan (weaknesses), peluang (opportunities), dan ancaman (threats). Analisis SWOT digunakan untuk menganalisispotensi kuliner di Kota Tangerang. Hasilnya adalah sebagai berikut:

1. Kekuatan (Strengths):

a. Banyaknya penyedia kuliner di Kota Tangerang yang menawarkan kuliner khas Kota Tangerang.

b. Kuliner di Kota Tangerang memiliki nilai sejarah.

c. Lokasi Kota Tangerang terletak diantara tiga kota besar.

d. Terdapat dukungan dari Pemerintahan Kota Tangerang untuk mengembangkan wisata kuliner di Kota Tangerang.

2. Kelemahan (Weaknesses):

a. Penyedia kuliner di Kota Tangerang belum memiliki standar kebersihan. b. Kurangnya promosi mengenai wisata kuliner di Kota Tangerang.

c. Kurangnya referensi mengenai kuliner yang memiliki nilai sejarah dan merepresentasikan Kota Tangerang.

3. Peluang (Opportunities):

a. Penetapan kawasan kuliner di Kota Tangerang, yaitu Kawasan Wisata Kuliner Pasar Lama dan Kawasan Kuliner Laksa Kota Tangerang.

b. Banyaknya wisatawan dari luar Kota Tangerang yang datang berkunjung untuk menikmati wisata kuliner di Kota Tangerang.

c. Banyaknya food blogger yang menggunakan media sosial untuk mempromosikan makanan dan minuman.

d. Munculnya aplikasi yang berisi informasi mengenai kuliner, seperti zomato dan tripadvisor.

4. Ancaman (Threats):

a. Penyedia kuliner di Kota Tangerang masih banyak yang berjualan dengan menggunakan gerobok sehingga pada saat hujan jumlah pembeli mengalami penurunan.

b. Pertumbuhan restoran cepat saji di Kota Tangerang yang berpotensi menurunkan penjualan makanan khas Kota Tangerang.

Berdasarkan analisis SWOT yang telah dilakukan, strategi dapat dikembangkan sebagai dasar dalam pengembangan wisata kuliner di Kota Tangerang. Empat pertimbangan strategi yang disarankan, yaitu strategi S-O (strength-opportunity), strategi WO (weakness-threat), strategi S-T (strengththreat) dan strategi W-T (weakness-threat):

1. Strategi S-O

a. Membuat kawasan kuliner yang khusus menawarkan kulier yang merepresentasikan Kota Tangerang.

b. Mengembangkan kerja sama dengan Pemerintah Daerah dari kota lain untuk mempromosikan kuliner di Kota Tangerang.

c. Mengundang food blogger untuk meliput tentang kuliner dilihat sejarah dan makanan dari para penyedia kuliner di Kota Tangerang.

2. Strategi W-O

a. Mengajak food blogger untuk meliput tentang kuliner dilihat dari segi kebersihan dari dari para penyedia kuliner di Kota Tangerang.

b. Mendorong para penyedia kuliner untuk melakukan promosi terkait produk kuliner yang ditawarkan. 
c. Mengembangkan kerja sama antara Pemerintah Kota Tangerang dengan pihak akademisi dalam penyusunan referensi dalam bentuk buku panduan wisata kuliner Kota Tangerang yang memiliki nilai sejarah dan merepresentasikan Kota Tangerang.

d. Menyediakan buku panduan di Tourist Information Center bagi wisatawan yang hendak melakukan wisata kuliner di Kota Tangerang.

3. Strategi S-T

a. Menyediakan fasilitas untuk meningkatkan daya saing para penyedia kuliner dan memberikan kenyamanan wisatawan.

b. Melakukan promosi mengenai wisata kuliner di Kota Tangerang.

4. Strategi W-T

a. Mendorong para penyedia kuliner untuk pengurusan standar kebersihan sehingga mampu memberikan jaminan kebersihan bagi wisatawan.

b. Melakukan promosi melalui media cetak, website resmi Pemerintah, maupun media sosial yang dimiliki oleh Pemerintah mengenai wisata kuliner di Kota Tangerang.

c. Mengembangkan kerja sama antara Pemerintah Kota Tangerang dengan pihak akademisi dalam menyusun referensi mengenai wisata kuliner di Kota Tangerang.

\subsection{Simpulan}

Pariwisata khususnya dalam bidang wisata kuliner saat ini menjadi suatu daya tarik tersendiri dan sangat pesat perkembangannya. Kota Tangerang merupakan kota dengan potensi wisata kuliner yang besar. Hal ini dibuktikan dengan banyaknya penyedia kuliner di kota ini yang menjual kuliner khas Kota Tangerang. Oleh karena itu, referensi sangat dibutuhkan untuk membantu para wisatawan dalam melakukan kegiatan wisatanya dan juga untuk mempromosikan wisata kuliner di Kota Tangerang. Selain itu, pengelolaan wisata kuliner di Kota Tangerang masih sangat diperlukan mengingat terdapat beberapa ancaman dan kekurangan yang dimiliki dalam pengembangan wisata kuliner di Kota Tangerang.

\section{Daftar Pustaka}

[1] Araujo, E. B. (2016). Pengembangan Kuliner Lokal Sebagai Daya Tarik Wisata di Dili, Timor Leste. Jurnal Master Pariwisata, Vol. 3 No. 1, 15-27.
[2] Badan Pusat Statistik Kota Tangerang (2012). Kota Tangerang dalam Angka 2012. Kota Tangerang: BPS Kota Tangerang.

[3] Besra, E. (2012). Potensi Wisata Kuliner Dalam Mendukung Pariwisata di Kota Padang. Jurnal Riset Akuntansi dan Bisnis, Vol. 12, No. 1, 74-101.

[4] Dewan Ketahanan Nasional (2016). Jumlah Pulau di Indonesia. Homepage online diakses dari https://dkn.go.id/ruang-opini/9/jumlahpulau-di-indonesia.html, pada tanggal 27 September 2017.

[5] Dittmer, P. R. dan Keefe, J. D. (2009). Principles of Food, Beverage, and Labor Cost Controls (9th ed.). New Jersey: John Wiley \& Sons, Inc.

[6] Ekawatiningsih (2008). Restoran Jilid I Untuk SMK. Jakarta: Direktorat Pembinaan Sekolah Menengah Kejuruan.

[7] Fitzsimmons, J. A. dan Fitzsimmons, M. J. (2006). Service Management: Operations, Strategy, Information Technology (5th ed.). New York: McGraw-Hill.

[8] Hall, C. M., Sharples, L., Mitchell, R., Macionis, N., dan Cambourne, B. (2003). Food Tourism Around the World: Development, Management, and Markets. Burlington: Butterworth-Heinemann.

[9] Harmayani, Eni, Santoso, Umar, dan Gardjito, Murdijati (2017). Makanan Tradisional Indonesia Seri 2: Makanan Tradisional Indonesia yang Populer. Yogyakarta: Gadjah Mada University Press

[10] Ismayanti (2010). Pengantar Pariwisata. Jakarta: PT Gramedia Widisarana Indonesia.

[11] Moleong, L. J. (2010). Metodologi Penelitian Kualitatif. Bandung: PT Remaja Rosdakarya.

[12] Pemerintahan Provinsi Banten (2014). Pemerintahan Kabupaten atau Kota. Homepage online diakses dari https://bantenprov.go.id/id/channel/pemka b.html, pada tanggal 23 Oktober 2017.

[13] Pendit, Nyoman S. (2003). IImu Pariwisata: Sebuah Pengantar Perdana. Jakarta: PT. Pradnya Paramitha.

[14] Raj, R., Griffin, K., dan Morpeth, N. (2013). Cultural Tourism. Boston: Cabi.

[15] Sekaran, U. dan Bougie, R. (2016). Research Methods For Business: A SkillBuilding Approach (7th ed.). West Sussex: John Wiley \& Sons.

[16] Sugiyono (2013). Metode Penelitian Kuantitatif, Kualitatif, dan R\&D. Bandung: Alfabeta. 
[17] Sumantri, A. (2010). Kesehatan Lingkungan. Jakarta: Kencana-Prenada Grup.
[18] Undang-Undang Republik Indonesia 2009 No. 10 Tahun 2009 tentang Kepariwisataan.

[19] Undang-Undang Republik Indonesia 2012 No. 18 tentang Pangan. 